\title{
"The application of Bhatt's knowledge management strategy in the organization of schools with the use of self-organized teams of teachers"
}

\begin{tabular}{ll} 
AUTHORS & $\begin{array}{l}\text { Mohammad Hassan Hassani Shalmani } \\
\text { Heidar Toorani }\end{array}$ \\
& $\begin{array}{l}\text { Mohammad Hassan Hassani Shalmani and Heidar Toorani (2016). The } \\
\text { application of Bhatt's knowledge management strategy in the organization of } \\
\text { schools with the use of self-organized teams of teachers. Problems and } \\
\text { Perspectives in Management, 14(3), 65-75. doi:10.21511/ppm.14(3).2016.06 }\end{array}$ \\
\hline ARTICLE INFO & http://dx.doi.org/10.21511/ppm.14(3).2016.06 \\
\hline DOI & Friday, 29 July 2016 \\
\hline RELEASED ON & "Problems and Perspectives in Management" \\
\hline JOURNAL & LLC “Consulting Publishing Company "Business Perspectives" \\
\hline FOUNDER &
\end{tabular}

NUMBER OF REFERENCES

0

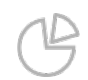

NUMBER OF FIGURES

0

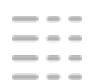

NUMBER OF TABLES

0

(C) The author(s) 2023. This publication is an open access article. 
Mohammad Hassan Hassani Shalmani (Iran), Heidar Toorani (Iran)

\title{
The application of Bhatt's knowledge management strategy in the organization of schools with the use of self-organized teams of teachers
}

\begin{abstract}
Education, to make maximum use of its human and physical resources, needs to establish social space-generating capacity to meet its goals. The most important problem, according to experts' opinions, which has damaged the effectiveness of schools, is the lack of a competitive environment schools. Therefore, it is required to draw up a framework to increase competition among schools. To establish such structure, several factors which facilitate implementation are required. Therefore, using the theoretical framework and experiences of countries, facilitating factors in applying the self-organized teams were extracted. Attitudes of teachers and administrators in relation to these factors should be investigated to measure the preparedness of education to apply these factors. This article with considering KAP research, which is focused on preparedness (knowledge), attitudes and behavior, attempts to concentrate on the establishing teachers' level of preparedness and achieving self-organized teams. For this purpose, using a questionnaire, attitudes of elementary school principals in Tehran were evaluated. The results show preparedness and a positive attitude of principals and teachers about the desired factors.
\end{abstract}

Keywords: knowledge management, self-organized teams of teachers, factors affecting the development of selforganized teams of teachers.

JEL Classification: I22.

\section{Introduction}

Knowledge management, in general terms, includes processes and operations which are concerned with the creation, acquisition, distribution and application of knowledge (Sales \& Jones, 2008). Knowledge creation is a floating combination of experiences, values, information dependent to a specific context and specialized insight. Knowledge provides a framework for evaluating and integrating new information and experience and it is formed in the minds of informed individuals. Such knowledge in organizations is not only often stored in documents, but also is concealed inside procedures, processes, practical and organizational norms (Downport \& Prozac, 2006). Knowledge creation is a process in which participation plays an important role.

When a group of people participate in the production or creation of knowledge, usually members produce parts of knowledge with their conception, afterwards, these components become integrated and coherent with each other. Such a participatory process in the creation of knowledge generally can be formed in teams (Rahnavard, 2006).

In order to create a capacity causing social environment in education, we are in need to identify factors which lead to goals in education. Since the main purpose of education is to provide the educational needs of the community until the end of secondary education with efficient, fair, proportional

(c) Mohammad Hassan Hassani Shalmani, Heidar Toorani, 2016.

Mohammad Hassan Hassani Shalmani, Ph.D., Research Institute of Education Studies, Iran.

Heidar Toorani, Ph.D., Associate Professor Research Institute of Education Studies, Iran. and adequate manner, and with regard to the limited financial resources to meet these extensive needs, they must inevitably include three features of effectiveness, fairness and appropriateness for possibility of adequate supply of needs to be achieved (Naderi, 2010, p. 70).

Experts believe that the main reason for inadequate funding supply of education in Iran is limited general resources; others point out to consuming nature of education's expenses. In contrast, some believe that the problems have roots in the ways of resource allocation (Institute of Education, 2004, p. 60). Improper use of facilities leads to inefficiency, which causes the lack of resources and intensifies financial needs. Furthermore, supply of financial resources not necessarily helps to qualitative and quantitative development of education. Unjust distribution of educational resources, as well as the inequalities in academic achievement are two serious issues that damage the proper enjoyment of all people (Naderi, 2010, p 70).

This article intends to identify factors that cause social capacity-generating environment in education to establish competition among schools. And through team self-organizing of teachers - which is one Bhatt's knowledge strategies - concede schools' management to qualified education teachers. In this way, through knowledge creation schools can empowered and trained, due to competitive environment.

\section{Problem statement}

The most important thing that has damaged the effectiveness of schools is the lack of a competitive market for schools (Naderi, 2010, p. 66). Lack of competitive market caused the effectiveness of schools 
become qualitatively minimized. Competitive market happens when, on the one hand, there is a demand for it and, on the other hand, there is a demand for attracting such demand. Otherwise, the market will be managed exclusively, in which customers have to use provided services with any quality. What is now seen in the governmental schools is monopoly in providing school education. There is no educational competition for governmental, because the provided education (schools) has no interest to attract demand, and for this school it will be much better even if the number of students become lesser, because the troubles will be less too; there is no competition for private schools, because demands for this schools are limited to top decile of people. So, to make schools competitive which makes schools performative (Naderi, 2010, p. 66), demand and supply for education are to be adjusted.

To establish a competitive educational market, in the first place, we need to develop education. This means that students from low deciles of society have access to private schools. Thus, the development of demands for education results in high quality supplied education in the schools. On the other hand, because of different characteristics of schools with other organizations due to some considerations such as cultural, social, political, etc., it isn't possible for schools to become completely private in any society. In this case, what should we do to: 1. Make our schools become competitive? (become efficient) 2 . Make educational demand and supply for competition 3. Consider characteristics of educational market. In other words, cause the participation of multiple beneficiaries (government, schools and parents). So, we need a model which takes into account multiple participation of educational beneficiaries (government, schools and parents).

Considering the major difference between the educational market and economical market due to social, political and cultural considerations, there is no possibility for completely private schools (Carnoy, 2001, p. 58). Therefore, for optimal use of existing capacities in education and in schools regulation of a kind of educational market is required in which, on the one hand, demands for private education get developed and, on the other hand, market's supplied education meets the community's and education systems' needs.

For this purpose, the proposal for the development of a competitive environment and market regulation which is aimed to present a model for educational supply and demand, is intended to provide model partnerships of public-private, in which governmental schools are self-organized by teachers and principals who are approved by Education Department, and ownership of the schools are maintained by government to monitor social, cultural, and political considerations. Through this project because of the capital costs omitting (land, buildings, plants) which is an important factor in increasing school tuition, school fees will being reduced. On the other hand, with transfer per pupil share to students in the form of drafts, instead of schools, the demand and development increased in the educational private market. As the demand for educational increases, a competitive environment in the education market and better-quality supplied education increases too, and more students aree attracted. On the other hand, it will result in increasing of motivation and empowering of teachers and improving of payments system based on competencies and establishing of performative management in schools.

\section{Literature review}

2.1. What is knowledge management? Davenport and Prusak (1998) view knowledge as an evolving mix of framed experience, values, contextual information, and expert insight that provides a framework for evaluating and incorporating new experiences and information. They found that, in organizations, knowledge often becomes embedded in documents or repositories and in organizational routines, processes, practices, and norms. They also say that, in order for knowledge to have value, it must include the human additions of context, experience, and interpretation.

Jennex (2005) defined KM as the practice of selectively applying knowledge from previous experiences of decision making to current and future decision making activities with the express purpose of improving the organization's effectiveness. Also, Jennex (2005) viewed a KM system as the system created to facilitate the capture, storage, retrieval, and reuse of knowledge. This perception of KM and $\mathrm{KM}$ systems is that they holistically combine organizational and technical solutions to achieve the goals of knowledge retention and reuse in order, ultimately, to improve organizational and individual decision making.

Managing knowledge never has been more important than in today's competitive environment (Desouza, 2003). The quantity of published research from the mid-1990s though 2005 shows increased effort to better understand knowledge management (KM). Despite this increased attention, several issues remain. There is dissention by both academia and practitioners over the true definition of knowledge management. There are also questions about the relevant constructs that comprise knowledge management and where our collective research has taken us in our efforts to discover those constructs (Jennex, 2007). 
Knowledge takes different forms and types. Perhaps, the most familiar distinction in the KM domain is between explicit and tacit knowledge (Nonaka, 1991). Other examples of knowledge include objective and experience-based knowledge (Penrose, 1959), organizational routines knowledge (Ashour, 2000), procedural knowledge (Kogut \& Zander, 1996; Nickolas, 2001; Winter, 1987), general (e.g., theoretical) knowledge and domainspecific (e.g., customer, technical, competitor, supplier, product, and market) knowledge (Demsetz, 1991; Grant, 1996), individual and organizational knowledge (Bhatt, 2001), external knowledge (i.e., produced by people outside the organization as resides in books, journals, magazines, etc.), and internal knowledge (i.e., created primarily within the organization, largely through experience and experimentation) (Jalote, 2003). Knowledge also can be viewed in a hierarchy of data, information, knowledge, and wisdom (Alavi \& Leidner, 2001; Davenport \& Prusak, 1998).

To manage knowledge efficiently, a firm needs a highly flexible and adaptable organizational structure. For example, Prahalad and Hamel (1990) suggest that, in present environments, organizations should structure on the basis of "core competencies", because these kinds of structures are inherently dynamic and flexible and they can sustain high level of environmental uncertainty and chaos (see also Nonaka, 1994). Knowledge management is, thus, a process of facilitating knowledge-related activities, such as creation, capture, transformation, and use of knowledge (Bhatt, 2000). The management process includes a range of activities ranging from learning, collaboration, and experimentation to integration of diverse sets of tasks and implementation of powerful information systems, such as Internet, intranet, and extranet.

2.2. Individual knowledge vs organizational knowledge. Some researchers such as Weick (1978) and Simon (1976) believed that organizations do not have the capacity to educate, but persons will be educated in organizations. Therefore, scholars such as Starbuck (1983) and Nelson and Winter (1982) believe that people upgrade according to their capacity to educate. Knowledge organizations learn knowledge through the process of their everyday business (Nilsson \& Winter, 1982).

Jennex (2006) describes how lower levels of social aggregation such as teams and work groups have shared contexts of understanding and readily can share and reuse knowledge with each other, while higher levels of social aggregation may have no understanding of the culture and context in which the knowledge was created and meant to be used, requiring users to have the story behind the knowledge.

In this way, daily knowledge becomes integrated with existing knowledge and new knowledge gets shaped on the basis of organizational culture (Barney, 1986). In this vision, organization is a unit which always encounters problems and tries to solve them. Learning that occurs in an organization is significantly affected by the complexity of the tasks and the organizational environment. Learning that takes place in an organization is significantly affected by the complexity of the tasks and the organizational environment. Accordingly, it is believed that, although the individual and organizational knowledge are distinct, they are inter-related, as far as the individual's interactions with others are related with organizational culture (Bhatt, 1998). Such interaction, in the current situation, because of the organizations' need to be responsible to their customers', is more obvious. On the other hand, in complex situations in which organizational tasks are more independent, and people cannot take action to solve interdisciplinary problems, employees are in need to cooperate with each other in order to benefit from each other's knowledge and experiences. Employees can cooperate various activities and solve complex problems by establishing consensus on common issues and analyses they conduct. Employees can resolve many of problems that organizations face with, based on areas of expertise, educational background and work experience. Organizations with complex nature of tasks, in which the use of interdisciplinary areas is required, employees need to have a high level of interaction, so that they can access to organizational knowledge. Contrary to separating of jobs which takes place through formal methods, knowledge sharing process is informal and social. Mentioned discussions emphasize on the importance of personal experience. For a better understanding of the relationship between individual knowledge and organizational knowledge, Bhatt's theoretical framework is depicted in Table 1. According to the objectives of discussion, the nature of the interaction and the nature of the tasks as two independent linear concepts of knowledge are important.

The horizontal axis in Table 1 refers to the interactive nature which can be in a range of down or dependent and up or independent. The vertical axis refers to the nature of the tasks that can be in a range from the normal and specific to the abnormal and non-specific. These two concepts create four classes of knowledge: 
Table 1 . The relationship between individual knowledge and organizational knowledge in view of Bhatt

\begin{tabular}{|c|c|c|}
\hline $\begin{array}{l}\text { Abnormal and non- } \\
\text { specific }\end{array}$ & Personal expertise (2) & $\begin{array}{l}\text { Cooperation, } \\
\text { coordination and } \\
\text { informal knowledge } \\
\text { sharing ( } 3 \text { ) }\end{array}$ \\
\hline$\uparrow$ task & Personal qualification (1) & $\begin{array}{l}\text { Methods, techniques } \\
\text { and formal rules (4) }\end{array}$ \\
\hline Normal and specific & \multicolumn{2}{|c|}{$\begin{array}{l}\text { Dependent Independent } \\
\text { Nature of interaction } \rightarrow\end{array}$} \\
\hline
\end{tabular}

1. First class: in this class, there is a low level of interaction among employees, and tasks of organization are ordinary and obvious. Under these circumstances, organizations empower their employees based on their own discretions. Considering that the current situation is dynamic and turbulent environment in which the organization, therefore, it is in need to be provided with a competitive advantage for commercializing (Stalk, 1988). In such an environment, organizations must empower their employees to be prepared to decide on immediate problems rather than try to investigate and solve it through a chain of actions.

2. Second class: in this class, there is a low degree of interaction, and nature of the task is unusual and non-specific. Not all persons have capability for solving specific and abnormal tasks, they need to be implemented with a high level of experience. Therefore, it is recommended for staff to directly perform unknown and unusual tasks on the basis of their expertise.

3. Third class: this class has a high degree of interaction and complex nature of the task. To be able to face with this situation, people need to constantly share their experiences, to develop coordination in the work. Because the nature of an organization depends on the coordination of duties, thus, in such an organization, the rules of coordination and knowledge sharing could not be dictated.

4. Fourth class: in this class, there is a high degree of interaction, and the nature of the task is normal and specific. In such circumstances, organizations often follow the formal rules and procedures. Most of the problems affecting the traditional organizations are related to this class, in which knowledge is determined through everyday issues and organizational reports. Rules, procedures and organizational structure ensure that an organization can coordinate tasks and business processes in an orderly manner.

2.3. Moving across all sectors. Although it is argued that any organization can accomplish its tasks with four types of knowledge, as shown in
Figure 1, this does not mean that the organization is unable to perform change tasks' performing from one section to another. In such situations, for instance, in the environments in which responsibility is one of the main factors of competitiveness of the organization, they can transfer performing from section 2 (which focuses on individual expertise) to section 3 (which focuses on cooperation).

\subsection{The role of organizations in developing} organizational knowledge. Table 1 indicates that one of the main factors of organizational knowledge is interaction. Organizations that have little organizational interaction are more likely to be in conditions in which that the knowledge is in control of persons, instead of organization. Therefore, a huge part of the knowledge is attained through informal interaction among internal staff (Bhatt, 1998). In this process, not only individuals enrich their knowledge, but also part of knowledge is created through these interactions. In other words, knowledge which internalized in organization is not created by the individuals in the organization, but is attained by their interactions. If personal knowledge cannot be related to interaction with others, it will be less effective to base organizational knowledge. Therefore, one of the most important management tasks is to provide facilities in the process of interaction and staff, and to bring sensitivity to environmental stimuli for employees, so that to strengthen and internalize their personal knowledge to help institutional knowledge (Nonaka, 1994). Deviation in the knowledge has great importance, because the process creates a new perspective on knowledge, and its validity is discussed in the group (Wieck, 1978).

2.5. Knowledge management in management strategies. Another categorization of knowledge management strategies has been provided by Dr. Bhatt (University of Maryland). According to studies conducted by Bhatt (2002), although expertise in individual levels is different with organizational knowledge, the organization cannot ignore the importance of personal knowledge controlling. If people don't have the necessary skills and knowledge, their interactions to create organizational knowledge valuable will be improbable. Therefore, the management objective is encouraging employees to increase interaction with people who have special expertise and skills to continually update their knowledge base. In Table 2, management strategies of several kinds of knowledge are shown, which is in the form of a process of creating, maintenance, transmission and application of knowledge to perform a specified task (Bhatt, 2002). 
Table 2. The relationship between individual knowledge and organizational knowledge in Bhatt's view

\begin{tabular}{|c|l|l|}
\hline \multirow{4}{*}{$\begin{array}{l}\text { Abnormal and non- } \\
\text { specific }\end{array}$} & $\begin{array}{l}\text { Establishing a } \\
\text { balance between } \\
\text { existing expertise and } \\
\text { creativity (2) }\end{array}$ & $\begin{array}{l}\text { Official meeting, Internet } \\
\text { newsgroups, and other } \\
\text { modes of collaboration } \\
\text { between staff (3) }\end{array}$ \\
\cline { 2 - 3 } Normal and specific & $\begin{array}{l}\text { Empowerment and } \\
\text { specific job and } \\
\text { education- related } \\
\text { business (1) }\end{array}$ & $\begin{array}{l}\text { Periodic review and } \\
\text { revision of the current } \\
\text { rules, policies and } \\
\text { procedures (4) }\end{array}$ \\
\cline { 2 - 3 } & \multicolumn{2}{|c|}{ Dependent Independent } \\
Nature of interaction $\rightarrow$
\end{tabular}

1. First strategy: in this strategy, the main challenge of management is to empower employees. Since employees are faced with the daily problems, they acquire a right understanding of the issues and opportunities through education. However, the degree of persons 'qualification will be determined on the basis of their professional experience. Management should also provide extensive guidance to apply staff's opinions. When employees are aware of the responsibilities and powers, it is likely to logically use selfopinions. The other goal of management should pursue further training of employees in order to connect them with daily tasks and processes. It means that, in addition to specialized task-based skills, it is necessary to receive necessary training to understand the hidden realities of business in today's dynamic and competitive environment. In order to get appropriate feedback from customers, respect to customers, accurate and timely responses to their needs, and being sensitive to customer, demand should be considered continually, so that management can re-evaluate staff competency levels and operate accordingly.

2. Second strategy: in this strategy, the main objective of managing is motivation and skill development of its experts. Management should not only provide a higher level of expectations of experts, but also they should encourage and reward them. Another way through which an organization can meet its responsibilities, is the use of smart and talented people (experts). Since most experts are very active and have individual characteristics, they continually seek freedom in carrying out their duties. Establishing balance between the requirements of the organization and creative professionals is vital for managing. Experts often follow their own agenda and do not care the limitations of the missions, goals and organizational strategies, and they do not see such issues as limits to apply their expertise within the organization. Therefore, management, in order to establish balance between the needs of organization (exploiting the knowledge of experts) and desires of experts (search for new knowledge), adopts appropriate methods. Microsoft, as a leading software company, has applied the efficiently management of this problem in knowledge management. The company not only encourages experts to take risks, but also has established a set of guidelines about resources of organization, programs, and projects which has been developed by experts.

3. Third strategy: in this strategy, the use of selforganized teams and social interactions which enhance and enrich the organizational basic knowledge should to be considered. Emphasis on information and multiple interpretations in addition to creating new realities, revive the commitment of the organization in order to replenish the knowledge-based concepts (Nonaka and Takchy, 1995). Process of multiple interpretation of knowledge is very important, because it allows people to reform and reshape their belief systems in connection with others. Organizations, in order to improve interactions among employees, can a use a wide variety of different perspectives, such as thinking, dialectical thinking (controversial) and the continuous experiences, and, to understand the market realities, they need to be sensitive to environmental stimuli which will be achieved through the creation of multiple perspectives on knowledge. In addition, multiple interpretation enable organizations in to assess the applicability and risk taking using a special kind of knowledge in various conditions. Since complex organizational tasks requiring in-depth analysis of issues, the role of management is important in establishing a cooperative atmosphere. However, the implementation of an organizational extensive solutions requires commitment from employees. If employees' views about solutions to organizational problems are not being considered, there will be the risk of vulnerability of the executive problems.

4. Fourth strategy: in this strategy, a major challenge for organizations is developing and coding rules and procedures in a simple format so that employees can easily earn and understand them. If rules and procedures are not clearly drafted, there is always possibility for each employee to have personal interpretations. When rules and procedures are clear, ambiguity in understanding and interpreting of them is reduced. Coding and standardization of tasks are among common means of resolving this ambiguity. Rules and regulations are not fixed throughout the life cycle 
of the organization. Along with the rapid changes in the external environment, it is necessary to carefully review the management of the rules, procedures and policies. If current rules, procedures and policies do not fit commercial facts, then, management should seek to invent new rules, procedures and policies. In other words, in order to be aligned with the changing realities, revision in laws, policies and practices is one of the most important goals of the company. A number of innovations and quality improvements which are undertaken by several companies fall under this classification.

2.6. Implementation of Bhatt's strategies in education. Due to the characteristics of education in complexity and accountability to education beneficiaries, Department of Education should improve their tasks to the level three strategies; therefore, factors which increase teachers' interaction with each other, are to be evaluated. Therefore, creating self-organized teams of teachers is dependent to establishing a competitive environment for these teams. Since development of competitive teams needs educational supply and demand conditions, therefore, it is necessary to increase the supply of students in the education market. On the other hand, because the main reason for lack of demand for private school is fees, and major factors of private schools' fees are renting and buildings costs. So, giving over schools (buildings) to such self-organized teams of teachers through cooperative companies can reduce fees and increase demands.

\section{Methods}

3.1. Research method. Permanent study of current situation is one of the most important requirements of any long-term planning based on sustainable development. It is this necessary study of current situation that gives significance to a certain type of study in different countries. Through these studies we can know which circumstances we are in, what is the direction of the society in terms of social and cultural variables, and on what factors variable are dependent. It is briefly called KAP studies. KAP is composed of the first letters of three words: Knowledge, Attitude and Practice. The awareness here means the process of organizing, interpreting and communicating information which are collected by the senses. The attitude means hidden mental structure in character and it can be defined as mentally preparation for confrontation with phenomena, issues, events and incidence of reactions with excitement. Practice is activities which can be viewed and explored (Alavitabar, 1380). This research aimed to measure the knowledge and attitudes of teachers is for its intended purpose.
According to purpose of study, which is team selforganization of teachers - one of the Bhatt's knowledge management strategies, this research tries to extract factors that affect the organization of teachers' teams'. Considering that extent and impact of each of these factors is carried out by using structural equation modeling, study is descriptive and causal correlational. The aim of this study is developmental. Type of data is combined (qualitative-quantitative); because the data to identify factors affecting public-private partnerships are collected through literature and theoretical and experts' opinions, so they are qualitative, and the data obtained from the questionnaires are quantitative.

\subsection{Statistical population, samples, sampling}

method. The study population are elementary school principals in primary schools of nineteen districts of Tehran in 2011. Considering the extent of schools in Tehran and to establish equal conditions in carrying out questionnaires by sending a circular letter from the Department of Education to Tehran's nineteen districts' schools and communicated it to primary schools from each district, the questionnaire was placed through the office automation on the website of the Education Department, and principles by entering the site printed questionnaires and returned them Education Department.

It should be noted that managers were obliged to complete the questionnaires, but, to participate in this study and only to note existing circulars of site, they were reminded by phone. Therefore, the sampling was targeted and available. For this reason, all principles of were primary schools and available sampling were considered, because: 1) it was expected that some reasons including lack of willingness to cooperate, workload, and some other considerations (such as management considerations) of the respondents caused them to refuse to participate, however, the sample size should have an extent that results not being undermined, 2) obtained specimens as much as possible should be representatives of the community and the number - which are going to be analyzed should be proportional and standard to operations, 3 ) in order to generalize the results, they should be more reliable.

Of the 1621 primary schools, 432 (27\%) questionnaires were delivered by principals to Education Department from 19 districts. Schools managers of which delivered questionnaires include: 351 state schools, 57 private schools, 10 schools directed by trustees boards, 5 schools for mentally disabled children, 1 school for families of martyrs, 1 school for gifted students, and 7 schools which types had not been specified by principles. Of the 
432 managers who delivered questionnaires, 259 $(60 \%)$ were female, $165(38.2 \%)$ were male, and 8 persons $(1.8 \%)$ not specified their gender. Of the 393 principles who reported their level of education: 10 principle $(2.3 \%)$ had diploma degree, $77(1.8 \%)$ associate degree, $275(63.7 \%)$ had license degree and $31(7.2 \%)$ had MA degree, and 39 persons (9\%) didn't report their level of education. The mean for work experience was 24.53 years with a standard deviation of 5.6 and the mean for years of management 11.23 years, with a standard deviation of 7.7 years.

3.3. Research instruments. Questionnaires were used to measure the knowledge and attitudes of teachers toward teachers' self-organization of team works. Research instrument is a researcher who made questionnaire to determine the program of government for self-organization of teachers' team works. Components were extracted based on the study of literature and concepts related to the application of participation in education in Iran and the world, at first, 136 variables covering all the concepts that are related to the application of the participation of teachers in education were explored. To interpret and coordinate data collection, with a combination of variables of 136 teachers' cooperation, the number was reduced to 7 programs to better consider their inter-relationship. It is hoped that a small number factors could cover almost all the information that is acquired by a larger set of variables, as a result, could simplify description of the persons' attitude. Furthermore, it is hoped, variables be created which imply a clear structure and a psychological sense, in a way that a person can be described not only simpler, but also clearer and more determined.
After determining the partnership of teachers based on a theoretical basis, questions on the seven-point Likert scale were divided. Scale degrees are: absolutely agree, strongly agree, agree, no opinion, disagree, strongly disagree, and absolutely disagree. Therefore, at above grading scale, those had chosen absolutely disagree had lowest agrees to perform the tasks of selforganization and teamwork of teachers and those who had chosen absolutely agree had the most of the agreements in implementation mentioned program. To validate second questionnaire content validity was used. For this purpose, the extracted concepts from the models and results of cooperation with 7 original concepts, were presented to 15 professors and experts in education and linguistics. All teachers and experts confirmed concepts of models and cooperation results of 7 original concepts.

\section{Results \& discussion}

4.1. Data analysis method. In order to analyze the data of this study, the descriptive analysis of the samples was used which includes the frequency, frequency percentage, gender of principles, districts, school types and education level of managers, work experience of principles; mean, standard deviation, maximum and minimum work an management experience were achieved. For effectiveness, structural equation modeling was used. Based on this model to determine the appropriateness of each components or entire questionnaire, as well as the participation rate of effectiveness was proved significantly. LISREL and SPSS were used to apply software descriptive and inferential statistics. The number of school principals according to level of education, gender and districts are as Table 3:

Table 3. Frequency of respondents to questionnaire of cooperation with separation of districts of Tehran

\begin{tabular}{|c|c|c|c|c|c|c|c|c|c|c|c|c|c|c|c|c|c|c|}
\hline $\begin{array}{c}\text { Districts of } \\
\text { Tehran }\end{array}$ & 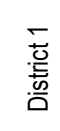 & 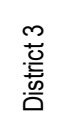 & 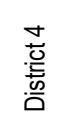 & 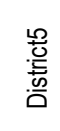 & 惫 & 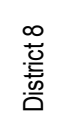 & 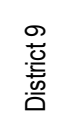 & 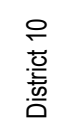 & 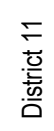 & 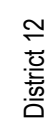 & 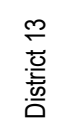 & 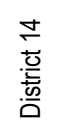 & 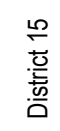 & 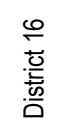 & 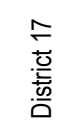 & 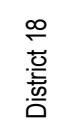 & 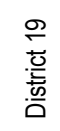 & 要 \\
\hline Frequency & 31 & 7 & 24 & 33 & 31 & 21 & 10 & 7 & 14 & 40 & 32 & 17 & 44 & 28 & 47 & 32 & 14 & 432 \\
\hline $\begin{array}{l}\text { Percent of } \\
\text { frequency }\end{array}$ & 7.2 & 1.6 & 5.6 & 7.6 & 7.2 & 4.9 & 2.3 & 1.6 & 3.2 & 9.3 & 7.4 & 3.9 & 10.2 & 6.5 & 10.9 & 7.4 & 3.2 & 100 \\
\hline
\end{tabular}

District 2 and District 6 of Education Depatments in Tehran did not cooperate.

The second part of the first section describes the response data from primary school principals to 7 questions on the questionnaire about the program and tasks that government can perform about public-private cooperation (giving out ownership of schools to the teachers with supervision of the state) is described:

Table 4. Response data description of principals' to the questions of program and supplementary tasks

\begin{tabular}{|c|c|c|c|c|c|c|c|c|c|c|c|}
\hline Questions & Indicators Options & 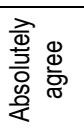 & 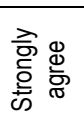 & $\frac{\Phi}{\frac{\Phi}{\alpha}}$ & $\begin{array}{l}\text { 을 } \\
\text { 흥 } \\
\text { 을 } \\
\text { 을 }\end{array}$ & 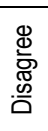 & 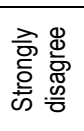 & 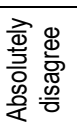 & 焉 & 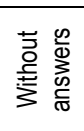 & 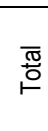 \\
\hline First question & Frequency & 106 & 31 & 128 & 42 & 82 & 13 & 19 & 421 & 11 & 432 \\
\hline
\end{tabular}


Table 4 (cont.). Response data description of principals' to the questions of program and supplementary tasks

\begin{tabular}{|c|c|c|c|c|c|c|c|c|c|c|c|}
\hline Questions & Indicators & 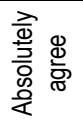 & 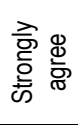 & 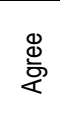 & 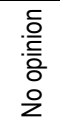 & 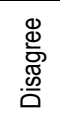 & 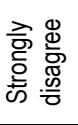 & 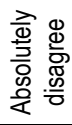 & 㶾 & 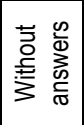 & 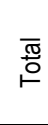 \\
\hline \multirow{2}{*}{ First question } & Percentage of frequency & 25.2 & 7.4 & 30.4 & 10 & 19.5 & 3.1 & 4.5 & 100 & & \\
\hline & Percentage of cumulative frequency & 25.2 & 32.5 & 62.9 & 72.9 & 92.4 & 95.5 & 100 & & & \\
\hline \multirow{3}{*}{ Second question } & Frequency & 60 & 35 & 100 & 60 & 118 & 18 & 30 & 421 & 11 & 32 \\
\hline & Percentage of frequency & 14.3 & 8.3 & 23.8 & 14.3 & 28 & 4.3 & 7.1 & 100 & & \\
\hline & Percentage of cumulative frequency & 14.3 & 22.6 & 46.3 & 60.6 & 88.6 & 92.9 & 100 & & & \\
\hline \multirow{3}{*}{ Third question } & Frequency & 144 & 62 & 149 & 30 & 33 & 2 & 5 & 425 & 7 & 432 \\
\hline & Percentage of frequency & 33.9 & 14.6 & 35.1 & 7.1 & 7.8 & 0.5 & 1.2 & 100 & & \\
\hline & Percentage of cumulative frequency & 33.9 & 48.5 & 83.5 & 90.6 & 98.4 & 98.8 & 100 & & & \\
\hline \multirow{3}{*}{ Fourth question } & Frequency & 120 & 65 & 132 & 35 & 55 & 4 & 12 & 423 & 9 & 423 \\
\hline & Percentage of frequency & 28.4 & 15.4 & 31.2 & 8.3 & 13 & 0.9 & 2.8 & 100 & & \\
\hline & Percentage of cumulative frequency & 28.4 & 43.7 & 74.9 & 83.2 & 96.2 & 97.2 & 100 & & & \\
\hline \multirow{3}{*}{ Fifth question } & Frequency & 136 & 62 & 142 & 47 & 25 & 3 & 5 & 420 & 12 & 432 \\
\hline & Percentage of frequency & 32.4 & 14.8 & 33.8 & 11.2 & 6 & 0.7 & 1.2 & 100 & & \\
\hline & Percentage of cumulative frequency & 32.4 & 47.1 & 81 & 92.1 & 98.1 & 98.8 & 100 & & & \\
\hline \multirow{3}{*}{ Sixth question } & Frequency & 167 & 67 & 136 & 32 & 18 & 1 & 3 & 424 & 8 & 432 \\
\hline & Percentage of frequency & 39.4 & 15.8 & 32.1 & 7.5 & 4.2 & 0.2 & 0.7 & 100 & & \\
\hline & Percentage of cumulative frequency & 39.4 & 55.2 & 87.3 & 94.8 & 99.1 & 99.3 & 100 & & & \\
\hline \multirow{3}{*}{ Seventh question } & Frequency & 177 & 59 & 116 & 32 & 29 & 7 & 10 & 425 & 7 & 432 \\
\hline & Percentage of frequency & 40.5 & 13.9 & 27.3 & 7.5 & 6.8 & 1.6 & 2.4 & 100 & & \\
\hline & Percentage of cumulative frequency & 40.5 & 54.4 & 81.6 & 89.2 & 96 & 97.6 & 100 & & & \\
\hline
\end{tabular}

Notes: first question: giving out management of schools to the teachers by maintaining ownership and supervision of government; second question: educational draft; third question: educational competition; fourth question: ranking of schools; fifth question: self-sufficiency schools; sixth question: mechanism of supply and demand (access right of children); seventh question: appropriateness of salary with qualifications of teachers.

As we can see in Table 4, including the "agree" option to as cut-off point (highlighted column in Table), attitudes of principals about in programs and functions to implement participation in schools are at high level, in which, maximum agreement is about the sixth question - the access right of children - with 87.3 percent - and the lowest agreement is for second question educational draft - with 43.6 percent.

Of course, if the option has to be added to this question than it shows that a high percentage of managers to implement programs and tasks of participation in schools are in agreement. After confirming the effectiveness of the participation, examine it. Of course, if we add "no opinion" option to this question, we can say that a high percentage of principal are in agreement about implementation of programs and tasks of participation in schools. After confirming the effectiveness of the participation, examine it. After confirming the level of influence, it is going to be examined as a factor of participation.
Analysis of structural equations. The results of structural equations for the use of selforganization participation of teachers' teams can be seen in Figure 1. Stands indicators and hidden variables in Table 5. In this diagram, can be seen. Abbreviation indicators and hidden variables in Table 5 can be seen in this diagram.

Table 5. Abbreviations of variables in SEM

\begin{tabular}{|l|c|}
\hline \multicolumn{1}{|c|}{ Variables } & $\begin{array}{c}\text { Abbreviations in } \\
\text { model }\end{array}$ \\
\hline $\begin{array}{l}\text { Giving out management of schools to the teachers by } \\
\text { maintaining ownership and supervision of government }\end{array}$ & $a 1$ \\
\hline Educational draft & $a 2$ \\
\hline Educational competition/selection & $a 3$ \\
\hline Quality Assurance (ranking) & $a 4$ \\
\hline Scientific and economic self-sufficiency & $a 5$ \\
\hline Educational justice & $a 6$ \\
\hline Different salaries for teachers & $a 7$ \\
\hline Variable of application indicators & Applicate \\
\hline
\end{tabular}

In Figure 1, the correlations of teams of teachers' implementation variables of participation of selforganizing (a1-a7) are depicted. 


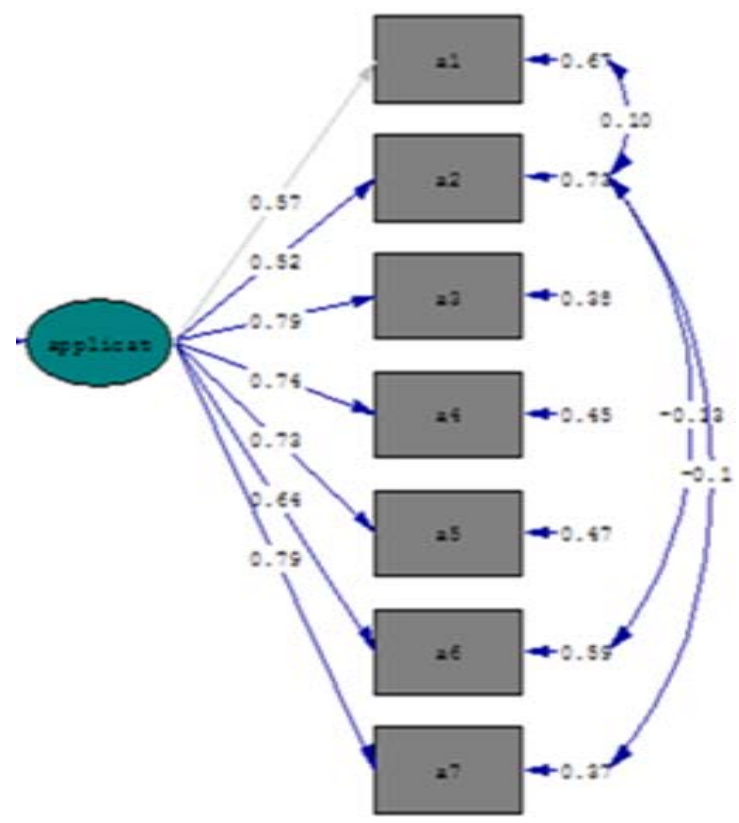

Fig. 1. Standard values of final model

Interpretation of structural equations amounts of model is used which defines the relationship final model. To interpret the values, measuring between the variables in Table 6 .

Table 6. Direct values measurement model

\begin{tabular}{|l|l|c|c|c|c|c|c|}
\hline \multicolumn{2}{|c|}{ Title relationship } & $\begin{array}{c}\text { Raw } \\
\text { estimation }\end{array}$ & $\begin{array}{c}\text { Standardized } \\
\text { estimation }\end{array}$ & $\begin{array}{c}\text { Standard error of } \\
\text { estimation }\end{array}$ & T-value & $\begin{array}{c}\text { Significance } \\
\text { level }\end{array}$ & \multicolumn{1}{|c|}{ Result } \\
\hline & $\begin{array}{l}\text { Government private sector } \\
\text { participation }\end{array}$ & 0.58 & 057 & - & - & - & \\
\cline { 2 - 7 } & Educational draft & 0.53 & 0.52 & 0.057 & 9.40 & $\mathrm{P}<0.01$ & $\begin{array}{l}\text { Confirmation of } \\
\text { direct effect }\end{array}$ \\
\cline { 2 - 8 } & Educational competition & 0.80 & 0.79 & 0.068 & 11.68 & $\mathrm{P}<0.01$ & $\begin{array}{l}\text { Confirmation of } \\
\text { direct effect }\end{array}$ \\
\cline { 2 - 8 } $\begin{array}{l}\text { Relation between } \\
\text { application on: }\end{array}$ & Standardization (ranking) & 0.75 & 0.74 & 0.067 & 11.29 & $\mathrm{P}<0.01$ & $\begin{array}{l}\text { Confirmation of } \\
\text { direct effect }\end{array}$ \\
\cline { 2 - 8 } & $\begin{array}{l}\text { Scientific and economic self- } \\
\text { sufficiency }\end{array}$ & 0.74 & 0.73 & 0.066 & 11.21 & $\mathrm{P}<0.01$ & $\begin{array}{l}\text { Confirmation of } \\
\text { direct effect }\end{array}$ \\
\cline { 2 - 8 } & Educational justice & 0.65 & 0.64 & 0.064 & 10.30 & $\mathrm{P}<0.01$ & $\begin{array}{l}\text { Confirmation of } \\
\text { direct effect }\end{array}$ \\
\cline { 2 - 7 } & $\begin{array}{l}\text { Salaries' appropriateness with } \\
\text { competence }\end{array}$ & 0,81 & 0.79 & 0.069 & 11.70 & $\mathrm{P}<0.01$ & $\begin{array}{l}\text { Confirmation of } \\
\text { direct effect }\end{array}$ \\
\hline
\end{tabular}

First column shows factor loading estimation through maximum likelihood method, these values are called $\lambda$ (Lambda) and show the relationship among hidden and manifest variables. In this model, participation does not have the $\mathrm{T}$-value and significance level, because, in the LISREL, there is a limitation for the first application of hidden variables, it means that there is no estimation for standard error value; so, there is no T-value estimation too. The second column shows the standard values of factor loading, which measures the standard relationship among indicators of measurement models. These values are comparable and facilitate the interpretation of relationships (Dutoit, 2007, p. 169). In T-value column, $\mathrm{T}$ is obtained estimation by dividing factor loading value on standard error of estimation column (indicating error value in raw estimation of factor loadings).

\section{Conclusion}

Due to the extracted factors, establishing a changing in approach in which there is moving from mere giving out of schools toward creating a competitive environment, with enhancing the competitiveness power of the private sector using governmental facilities for self-organization of teachers' teams in primary schools of Tehran, depends on changes and approaches, important ones of which are going to be mentioned:

1. For self-organization of teachers, we need to increase demand through greater access of students to schools. In order to make schools more responsive to students, students' per capita can be given them in the form of educational coupons. In this case, self-organized schools, at the end of each month, based on the number of 
students who give their names to Education Departments receive per capita.

2. Such conditions can be developed through the formation of NGOs; teacher-based institutions which take shape on the basis of selforganization of qualified teachers, can also shift to knowledge-based firms.

3. Self-organization teachers leads to a sense of belonging and psychological ownership. It also removes teachers' institutional indifference, and results to schools' self-sufficiency.

4. Transferring schools by the government to selforganized teams of teachers, leads to more government supervision based on initial contracts which are signed by teachers as of institutions, and it makes clear expectations from schools.

5. Establishing a competitive environment for selfsufficient teachers' teams, leads to increasing of quality to attract more students.

6. Outsourcing of education and giving out school affairs to qualified leads to Ministry of Education and Training tend to major programs of education and training.

7. According to the results in which government's programs and tasks are significant, Education
Ministry can, based on fourth application (ranking of schools), regulate property rights, and establish educational standards for competitiveness of schools to provide academic ranking.

8. According to significance impact of models extracted from government's programs and tasks, Education Ministry, based fifth application (scientific-economic self-sufficiency of schools), can optimize schools' expenses. These conditions which require promotion of property rights in schools lead to knowledge added value for schools.

9. According to the results, based on the sixth application (providing access for low-income students), Education Ministry should create a competitive situation, which results in educational justice.

10. According to significance impact of models extracted from government's programs and tasks in the cooperation and management, on the basis of seventh application (different payment for teachers based on merit), Education Ministry can improve the quality of school education and with developing standards for teacher pave the way for forming a system of teachers.

\section{References}

1. Alavi, M. \& Leidner, D.E. (2001). Review: Knowledge management and knowledge anagement systems: Conceptual foundations and research issues, MIS Quarterly, 25 (1), pp. 107-136.

2. Alan, M. \& Wendy, M.J. (2008). Introduction to Psychometric theory (psychometric). (Translated by Ali Delavr). Tehran: Samt Publication.

3. Ansari, A. (2010). The Role of Government in the Financing of Education. Institute of Education Studies: Quarterly Journal of Education, 104, pp. 31-58.

4. Bhatt, G. (1998). Managing knowledge through people, Knowledge and Process Management: Journal of Business Transformation, 5 (3), pp. 165-171.

5. Bhatt, G. (2002). Management strategies for individual knowledge and organizational knowledge, Journal of Knowledge Management, 6 (1), pp. 31-39.

6. Barney, J.B. (1986). Strategic factor markets: expectations, luck, and business strategy, Management Science, 32 , pp. 1231-1241.

7. Blanchard, K., Carlos, J. \& Randolph, A. (2002). Enabling Employees. (Translated by M. Irannejad Parizi), Karaj: Research and Management Training Research Institute.

8. Carnoy, M. (2001). Political Economy in the Production Process of Education. (Translation A. Nafisi), Encyclopedia of Economics of Education, Tehran: Institute of Education.

9. Danayifard, H. (2010). Designing Criteria for Measuring Organizational Indifference: Compound Research, The Idea of Strategic Management, 4 (2).

10. Davenport, T.H. \& Prusak, L. (1998). Working knowledge. Boston: Harvard Business School Press.

11. Desouza, K.C. (2003). Strategic contributions of game rooms to knowledge management: Some preliminary insights, Information \& Management, 41 (4), pp. 63-75.

12. Dutoit, S. \& Dutoit, M. (2007). Conversational Lisrel. (Translated by A. Delavaree, H. Veyskarami, M. Zarinjooyi). Tehran: Arasbaran Publication.

13. Firestone, J. \& Elroy, M. (2008). Key Issues in the Management of New Knowledge. (Translated by A. Jafarnejad, Kh. Safiri). Tehran: Mehrban Nashr Publication.

14. Jennex, M.E. (2005). What is KM? International Journal of Knowledge Management, 1 (4), pp. 1-4.

15. Jennex, M.E. (2006). Classifying knowledge management systems based on context content. In Proceedings of the Hawaii International Conference on Systems Sciences, IEEE.

16. Jennex, M.E. (2007). Knowledge Management in Modern Organizations, San Dego Unversty, USA.

17. Nader, A. (2009). Finance of Education. Tehran: Tehran University Publication.

18. Naderi, A. (2010). Mechanism and Desired Pattern Allocation for Education: Principles, Requirements, Elements and Algorithms, Quarterly journal of education, Institute of Education Studies, 104, pp. 59-90. 
19. Nelson, R.R. \& Winter, S.G. (1982). An Evolutionary Theory of Economic Change. Cambridge, MA: Belknap Press of Harvard University.

20. Nonaka, I. (1994). A dynamic theory of organizational knowledge creation, Organization Science, 5 (1), pp. 14-37.

21. Nonaka, I. and Takeuchi, H. (1995). The Knowledge Creating Company \pm How Japanese Companies Create the Dynamics of Innovation. Oxford: Oxford University Press.

22. Prahalad, C.K. and Hamel, G. (1990). The core competence of the corporation, Harvard Business Review, 68 (3), pp. 79-93.

23. Rahnavard, F. (2006). Vision of Participation. Tehran: Research Institute of Planning and Management.

24. Research Institute of education and training. (2004). Estimation of Education's Actual Share of the State Budget. Tehran: Research Institute of education and training, Department of Economics Education. Research Institute of Education Studies.

25. Sales, E. \& Jones, G. (2008) Knowledge Management In Educational Organizations. (Translated by M. Ahanchian, R. Hussainqolizade). Tehran: The Institute of Education Studies.

26. Simon, H.A. (1976). Administrative Behavior: A Study of Decision-making Processes in Administrative Organization. 3rd ed. New York: Free Press.

27. Stalk, G. (1988). Time \pm the next source of competitive advantage, Harvard Business Review, 66 (4), pp. 41-55.

28. Supreme Council of the Cultural Revolution. (1390). Document of Fundamental Transformation of Education. Tehran: Supreme Council of the Cultural Revolution.

29. Weick, K.E. (1978). The Social Psychology of Organizing. Reading, MA: Addison-Wesley Publishing. 